\title{
HUBUNGAN KARAKTERISTIK SOSIAL EKONOMI PETANI PADI SAWAH DENGAN KEI- KUTSERTAAN DALAM PENYULUHAN PERTANIAN DI DESA KAMANGA KECAMATAN TOMPASO KABUPATEN MINAHASA
}

\author{
Welson Marthen Wangke
}

\begin{abstract}
This study aims to analyze the relationship between socio-economic characteristics rice farmers in participating in agricultural extension in the Village District of Tompaso Kamanga.

The method used in this research is quantitative method. The research was conducted in the Village District of Tompaso Kamanga Minahasa regency. The number of respondents were 30 farmers: Simple Random Sampling. By using questionnaires. The variables measured were: age is measured in (year), education is formal education (elementary Graduate, Graduate from junior high school, go to college, PT), revenue is measured from the income of the paddy rice farming (USD), the status of land ownership (see from their own land and tenants and or penyakap), participation in agricultural extension (seen from the frequency of attendance). To determine the socio-economic factors that influence the selection of a variety of extension methods used Spearman Rank correlation formula (Siegel, 1997). The results showed that the characteristics of the members of the real touch with the level of participation and vice versa if the value of the probability $(P)>\alpha$, mean that there is no real relationship between the characteristics of the members of the participation rate.
\end{abstract}

Keywords: Relationship, Characteristics, Farmers, Agricultural Extension

\section{PENDAHULUAN}

Penyuluhan pertanian diartikan sebagai proses pembelajaran pelaku utama dan pelaku usaha agar mau dan mampu menolong dirinya dalam mengakses informasi, teknologi, permodalan, dan sumber lainnya sebagai upaya untuk meningkatkan produktivitas, efisiensi usaha pendapatan dan kesejahteraan serta meningkatkan kesatuan dalam pelestarian fungsi lingkungan hidup. Jadi, petani dibantu agar dapat membantu diri sendiri, dididik agar dapat mendidik diri sendiri (UU no.16/2006) .

Menurut Dahama dan Bhatnagar (Departemem Pendidikan Nasional: 2006), prinsip-prinsip penyuluhan itu adalah: a) minat dan kebutuhan artinya penyuluhan pertanian akan efektif jika selalu mengacu kepada minat dan kebutuhan masyarakat mengenai hal ini harus dikaji secara mendalam apa yang harus menjadi minat dan kebutuhan yang dapat menyenangkan setiap individu maupun segenap masyarakatnya, b) organisasi masyarakat bawah artinya penyuluhan pertanian akan efektif jika mampu melibatkan/membentuk organisasi masyarakat bawah, sejak dari setiap keluarga/kekerabatan, c) keragaman budaya artinya penyuluh pertanian harus memperhatikan adanya keragaman budaya. Perencanaan penyuluhan pertanian harus selalu disesuaikan dengan budaya lokal yang neraga, d) perubahan budaya artinya setiap kegiatan penyuluhan pertanian mengakibatkan perubahan budaya yang harus dilaksanakan dengan bijak dan hati-hati agar perubahan yang terjadi tidak menimbulkan kejutan-kejutan budaya.

Jalan yang diyakini dapat mengatasi permasalahan (ketidakberdayaan) petani dan membebaskan manusia petani dari kemiskinan adalah melalui pendidikan. Yang menjadi pertanyaan pendidikan seperti apakah yang dibutuhkan petani untuk membebaskan, memanusiakan dan pada akhirnya mengubah situasi hidupnya. Karakteristik sasaran termasuk salah satu faktor yang dipertimbangkan dalam kegiatan penyuluhan agar mendukung efektivitas penyampaian pesan pembangunan. Beberapa 
hasil penelitian tentang karakteristik keinovatifan antara lain dilakukan oleh Subagiyo (2005), di mana karakteristik yang berkaitan dengan keinovatifan petani dalam menerima informasi dan inovasi antara lain umur, tingkat pendidikan dan pengalaman bekerja, motivasi, terhadap informasi dari media, kekosmopolitan, serta keterlibatan dalam organisasi.

\section{Perumusan Masalah}

Berdasarkan uraian pada latar belakang maka dirumuskan masalah yaitu bagaimana hubungan karakteristik sosial ekonomi petani padi sawah dengan keikutsertaan dalam penyuluan pertanian di Desa Kamanga Kecamatan Tompaso.

\section{Tujuan Penelitian}

Menganalisis hubungan antara karakteristik sosial ekonomi petani padi sawah dengan keikutsertaan dalam penyuluhan pertanian di Desa Kamanga Kecamatan Tompaso.

\section{METODOLOGI PENELITIAN}

\section{Waktu dan Tempat}

Penelitian ini dilaksanakan di Desa Kamanga Kecamatan Tompaso Kabupaten Minahasa pada bulan Oktober 2011. Jumlah responden sebanyak 30 petani secara: " Simple Random Sampling". Dengan menggunakan daftar pertyanyaan.

\section{Metode Analisis Data}

Untuk mengetahui faktor-faktor sosial ekonomi yang berpengaruh terhadap pemilihan ragam metode penyuluhan digunakan rumus korelasi Rank Spearman (Siegel, 1997), yaitu :

$$
\mathrm{rs}=1-\frac{\partial \sum d^{2}}{n\left(n^{2}-1\right)}
$$

\section{Dimana :}

$$
\begin{array}{ll}
\mathrm{n} & \text { : jumlah responden } \\
\mathrm{Rs} & : \text { koefisien korelasi rank spearman } \\
\mathrm{d}^{2} & : \text { selisih ranking } \\
\partial & \text { : angka konstan, } \alpha=0,05
\end{array}
$$

\section{Hipotesis}

Berasarkan latar belakang perumusan masalah, tujuan penelitian, tinjauan pustakan dan kerangka pemikiran maka dirumuskan hipotesis penelitian sebagai berikut:

Ada hubungan nyata antara umur petani dengan keikutsertaan dalam kegiatan penyuluhan pertanian. Makin muda umur petani semakin tinggi keikutsertaannya dalam penyuluhan pertanian.

Ada hubungan nyata antar tingkat pendidikan petani dengan tingkat keikutsertaan dalam penyuluhan pertanian. Makin tinggi tingkat pendidikan semakin tinggi keikutsertaan dalam penyuluhan pertanian..

Ada hubungan nyata antara tingkat pendapatan petani dengan keikutsertaan petani dalam penyuluhan pertanian. Makin tinggi pendapatan petani makin tinggi keikutsertaan dalam penyuluhan pertanian.

Ada hubungan nyata antara status pemilikan tanah petani dengan keikutsertaan dalam penyuluhan pertanian. Status pemilikan milik sendiri keikutsertaannya lebih tinggi daripada petani penggarap dan atau penyakap.

\section{Konsepsi Pengukuran Variabel}

Dari hipotesis yang telah dirumuskan, maka definisi operasionalnya dan pengukuran masing-masing variabel adalah sebagai berikut:

Umur adalah usia petani pada saat wawancara yang dinyatakan dalam tahun. Dikategorikan sebagai berikut:

Umur muda $=\leq 46$ tahun

Umur sedang $=47-60$ tahun

Umur tua $=\geq 61$ tahun

Tingkat pendidikan adalah tingkat pendidikan formal tertinggi yang pernah dicapai oleh petani, dikategorikan ke dalam tiga golongan:

Rendah $=$ Tamat SD

Sedang $=$ Tamat SMP

Tinggi $=$ Tamat SMA ke Atas (Diploma dan S1)

Tingkat pendapatan adalah total pendapatan yang diperoleh rumah tangga petani dari usahatani maupun luar usahatani per satuan waktu.

Kategori:

Rendah $=\leq 1.000 .000$ 
Sedang $=1.500 .000-4.500 .000$

Tinggi $=\geq 5.000 .000$

Status kepemilikan lahan dibagi atas 2 (dua) kategori kedudukan petani sebagai pemilik dan kategori petani sebagai penyewa dan atau penyakap. Kategori pemilik lahan skore $=1$ dan penggarap, dan atau penyakap skore $=2$.

Keikutsertaan petani dalam penyuluhan pertanian adalah keterlibatan petani dalam kegiatan-kegiatan yang diselenggarakan oleh penyuluh pertanian (kegiatan penerapan teknologi kegiatan mencari informasi, kegiatan perencanaan dan evaluasi).

Kategori:

Rendah $=$ jumlah skor $17-24$

Sedang $=$ jumlah skor $25-32$

Tinggi $=$ jumlah skor $33-39$

\section{HASIL PENELITIAN DAN PEMBAHASAN}

\section{Umur dan Tingkat Partisipasi Anggota Ke- lompok Tani}

Umur anggota kelompok tani dibedakan menjadi tiga golongan, yaitu umur muda ( $\leq 46$ tahun), umur sedang (47 - 60 tahun) dan umur tua ( $\geq 61$ tahun). Sebaran anggota menurut tingkat umurnya dapat dilihat pada Tabel 1. Distribusi tingkat umur petani sebagian besar berusia sedang yaitu sebanyak 43,33\%, Sedangkan yang berusia muda dan tua masing-masing sebanyak 23,33 $\%$ dan $33,33 \%$.

Tabel 1. Distribusi Tingkat Umur Petani Responden di Desa Kamanga Kecamatan Tompaso

\begin{tabular}{|l|l|l|}
\hline Tingkat Umur & Jumlah & Presentase(\%) \\
\hline $\begin{array}{l}\text { Muda }(\leq 46 \text { ta- } \\
\text { hun) }\end{array}$ & 7 & 23,33 \\
\hline $\begin{array}{l}\text { Sedang (47 }-60 \\
\text { tahun) }\end{array}$ & 13 & 43,34 \\
\hline Tua ( $\geq 61$ tahun) & 10 & 33,33 \\
\hline Jumlah & 30 & 100 \\
\hline
\end{tabular}

Dalam hipotesis dinyatakan bahwa umur mempengaruhi tingkat partisipasi petani, yaitu semakin muda umur, tingkat partisipasinya semakin tinggi. Hal ini disebabkan karena kelompok umur muda memiliki wawasan dan pandangan ke depan yang lebih baik dibandingkan dengan kelompok umur tua(Lalaenoh, 1994). Dan sejalan dengan itu Tamadi (1994) menyatakan bahwa petani yang sudah tua cenderung daya tahan tubuhnya sudah berkurang, dengan demikian kemampuannya untuk berpartisipasi dalam berbagai kegiatan akan berkurang.

Dari hasil penelitian ditemukan pada kelompok umur muda, kelompok umur sedang dan kelompok umur tua, cenderung berpartisipasi pada tingkat sedang yaitu masing-masing sebesar $66,67 \%$; 61,54\%. Dan 70\% Hal ini dapat dilihat pada Tabel 2. Jadi dapat dikatakan bahwa tingkat partisipasi anggota pada setiap kelompok umur cenderung sedang. Hal ini disebabkan karena anggota menyadari pentingnya kelompok tani sebagai wadah kerjasama dalam melaksanakan kegiatan usahatani mereka tanpa memandang umur mereka.

Tabel 2. Distribusi Anggota Menurut Tingkat Umur dan Tingkat Partisipasi Pada Kelompok Tani Desa Kamanga Kecamatan Tompaso

\begin{tabular}{|l|l|l|l|}
\hline \multirow{2}{*}{$\begin{array}{l}\text { Tingkat } \\
\text { tisipasi }\end{array}$} & Par- & \multicolumn{3}{l|}{ Tingkat Umur } \\
\cline { 2 - 4 } & Muda & Sedang & Tua \\
\hline Rendah & 1 & 2 & 1 \\
& $(16,67)$ & $(15,38)$ & $(10)$ \\
\hline Sedang & 4 & 8 & 7 \\
& $(66,67)$ & $(61,54)$ & $(70)$ \\
\hline Tinggi & 1 & 3 & 2 \\
& $(16,67)$ & $(23,08)$ & $(20)$ \\
\hline Jumlah & 6 & 13 & 10 \\
\hline Keterangan :angka pada ( ) adalah persentase
\end{tabular}

Hal ini diperkuat dengan uji Korelasi Spearman yang menunjukkan tidak ada hubungan yang nyata antara umur dengan tingkat partisipasi anggota. Dari hasil analisis diperoleh nilai $P=0,29>\alpha=$ 0,05 . Hal ini menunjukkan karakteristik umur 
tidak mempengaruhi tingkat partisipasi petani dalam kelompok tani.

\section{Pendidikan dan Keikutsertaan dalam Penyu- luhan Pertanian}

Pendidikan seseorang mempunyai pengaruh terhadap keikutsertaan dalam penyuluhan. Makin tinggi tingkat pendidikan yang ditempuh maka makin tinggi keikutsertaan dalam penyuluhan pertanian. Karena dengan semakin tinggi tingkat pendidikan semakin mudah untuk diberi pengertian dan pembinaan(Ajiswarman, 1996).

Tingkat pendidikan dalam penelitan ini dikelompokkan menjadi tiga yaitu rendah, sedang dan tinggi. Kelompok tingkat pendidikan rendah adalah kelompok petani yang tamat SD. Kelompok tingkat pendidikan sedang adalah petani yang tamat SMP dan tingkat pendidikan tinggi yaitu petani yang tamat SMA ke atas. Pada Tabel 3 di bawah ini dapat dilihat sebaran anggota menurut tingkat pendidikanya. Berdasarkan tabel tersebut diketahui bahwa sebagian besar petani yaitu 53,33 $\%$ tergolong dalam kategori pendidikan rendah yaitu menempuh pendidikan hanya sampai SD. Sedang yang menempuh pendidikan SMP sebesar $26,67 \%$, serta yang tergolong pendidikan tinggi yaitu SMA ke atas hanya $20 \%$.

Tabel 3. Distribusi Petani Menurut Tingkat Pendidikan di desa Kamangan Kecamatan Tompaso

\begin{tabular}{|l|l|l|}
\hline Tingkat Pendidikan & Jumlah & $\begin{array}{c}\text { Presentase } \\
(\%)\end{array}$ \\
\hline $\begin{array}{l}\text { Rendah } \\
\text { (Tamat SD) }\end{array}$ & 16 & 53,33 \\
\hline $\begin{array}{l}\text { Sedang } \\
\text { (Tamat SMP) }\end{array}$ & 8 & 26,67 \\
\hline $\begin{array}{l}\text { Tinggi Se } \\
\text { (Tamat SMA ke } \\
\text { Atas) }\end{array}$ & 6 & 20 \\
\hline Jumlah & 30 & 100 \\
\hline
\end{tabular}

Sebaran responden menurut pendidikan dan keikutsertaan dalam penyuluhan pertanian, dapat dilihat bahwa kecenderungan sedang, lihat Tabel 4.
Tabel 4. Hubungan Pendidikan Petani dan Keikutsertaan dalam Penyuluhan Pertanian

\begin{tabular}{|l|l|l|l|}
\hline \multirow{2}{*}{$\begin{array}{l}\text { Tingkat Par- } \\
\text { tisipasi }\end{array}$} & Tingkat Pendidikan \\
\cline { 2 - 4 } & Rendah & Sedang & Tinggi \\
\hline Rendah & 6 & 2 & 0 \\
& $(42,86)$ & $(40)$ & $(0)$ \\
\hline Sedang & 7 & 2 & 3 \\
& $(50)$ & $(40)$ & $(27,27)$ \\
\hline Tinggi & 1 & 1 & 8 \\
& $(7,14)$ & $(20)$ & $(72,73)$ \\
\hline Jumlah & 14 & 5 & 11 \\
& $(100)$ & $(100)$ & $(100)$ \\
\hline
\end{tabular}

Dari Tabel 4 terlihat petani yang berpendidikan rendah sebagian besar $(50 \%)$ berpartisipasi sedang. Pada kelompok anggota yang berpendidikan sedang sebagian berpartisipasi sedang. Terli pula bahwa pada tingkat pendidikan tinggi, anggota yang berpartisipasi tinggi, lebih besar dari kelompok lainnya yaitu sebesar $72,73 \%$. Hal ini disebabkan karena anggota yang berpendidikan tinggi mudah untuk diberi pengertian dan pembinaan. Mereka aktif dalam mencari informasi mengenai kegiatan usahataninya, karena mereka mengetahui bahwa hal itu penting dalam rangka peningkatan produksi mereka.

Berdasarkan hasil uji korelasi Spearmen juga menunjukkan adanya hubungan yang nyata antara tingkat pendidikan dan tingkat partisipasi. Hasil uji ini menghasilkan $P=0,020<\alpha=0,05$.

Jadi dapat disimpulkan bahwa tingkat pendidikan mempengaruhi partisipasi anggota kelompok tani, yaitu makin tinggi tingkat pendidikan petani maka semakin tinggi tingkat partisipasinya dalam kelompok tani.

\section{Pendapatan dan Keikutsertaan dalam Penyu- luhan Pertanian}

Pendapatan petani mempunyai pengaruh terhadap keikutsertaan petani dalam penyuluhan pertanian. Makin tinggi tingkat pendapatan, semakin tinggi keikutsertaannya dalam penyuluhan pertanian. Distribusi pada tabel 5 menunjukkan bahwa sebagian besar ( 50\%) anggota kelompok tani mempunyai pendapatan sedang.

Tabel 5. Distribusi Petani Menurut Pendapatan 


\begin{tabular}{|l|l|l|}
\hline Tingkat Pendapatan & Jumlah & Presentase (\%) \\
\hline Rendah & 7 & 23,33 \\
\hline Sedang & 15 & 50 \\
\hline Tinggi & 8 & 26,67 \\
\hline Jumlah & 30 & 100 \\
\hline
\end{tabular}

Hubungan antara tingkat pendapatan anggota kelompok tani dengan keikutsertaan dapat dilihat pada Tabel 6 .

Tabel 6. Hubungan Petani Menurut Pendapatan dan Keikutsertaan dalam Penyuluhan Pertanian

\begin{tabular}{|c|c|c|c|}
\hline \multirow{2}{*}{$\begin{array}{l}\text { Keikutsertaan } \\
\text { Dalam Penyu- } \\
\text { luhan Perta- } \\
\text { nian }\end{array}$} & \multicolumn{3}{|c|}{ Tingkat Pendapatan } \\
\hline & Rendah & Sedang & Tinggi \\
\hline Rendah & $\begin{array}{l}6 \\
(28,57)\end{array}$ & $\begin{array}{l}0 \\
(0))\end{array}$ & $\begin{array}{l}0 \\
(0)\end{array}$ \\
\hline Sedang & $\begin{array}{l}10 \\
(47,62)\end{array}$ & $\begin{array}{l}1 \\
(20)\end{array}$ & $\begin{array}{l}2 \\
(50)\end{array}$ \\
\hline Tinggi & $\begin{array}{l}5 \\
(23,80)\end{array}$ & $\begin{array}{l}4 \\
(80)\end{array}$ & $\begin{array}{l}2 \\
(50)\end{array}$ \\
\hline Jumlah & $\begin{array}{l}21 \\
(100)\end{array}$ & $\begin{array}{l}5 \\
(100)\end{array}$ & $\begin{array}{l}4 \\
(100)\end{array}$ \\
\hline
\end{tabular}

Pada Tabel 6 terlihat bahwa petani yang mempunyai tingkat pendapatan sedang dan tinggi, tidak ada yang berpartisipasi rendah. Namun pada kelompok tingkat pendidikan rendah ada $23,80 \%$ yang berpartisipasi rendah. Hal ini berhubungan dengan kemampuan petani, dalam hal ini modal berusahatani, dalam hal ini modal berusahatani, dimana petani yang mempunyai tingkat pendapatan rendah tidak mampu untuk membeli sarana produksi usahataninya sehingga mereka tidak dapat menerapkan teknologi. Sebaliknya pada anggota yang mempunyai tingkat pendapatan sedang dan tinggi, lebih mampu untuk membeli sarana produksi untuk usahataninya.

Hal ini didukung dengan uji Korelasi Spearmen, di mana diperoleh hasil $P=0.00<\alpha$ $=0,05$. Hal ini berarti ada hubungan yang nyata atau positif antara status sosial ekonomi dengan tingkat partisipasi, yaitu makin tinggi status sosial ekonomi petani, maka semakin tinggi tingkat partisipasinya sebagai anggota kelompok tani.

\section{Luas Lahan dan Keikutsertaan dalam Penyu- luhan Pertanian}

Luas Lahan dibagi atas 3 (tiga) kategori yaitu $<0,5 \mathrm{Ha}$ (Kecil); 0,5-1 Ha (Sedang) dan $>1$ Ha (Besar). Hal ini dapat dilihat pada Tabel 7.

Tabel 7. Distribusi Luas Lahan dan Jumlah Petani

\begin{tabular}{|l|l|l|}
\hline \multicolumn{1}{|c|}{$\begin{array}{c}\text { Luas Sawah } \\
\text { (ha) }\end{array}$} & \multicolumn{1}{|c|}{ Jumlah } & \multicolumn{1}{|c|}{$\begin{array}{c}\text { Presentase } \\
(\%)\end{array}$} \\
\hline$<0,5$ & 12 & 40 \\
\hline $0.5-1$ & 17 & 56,67 \\
\hline$>1$ & 1 & 3,33 \\
\hline Jumlah & 30 & 100 \\
\hline
\end{tabular}

Dari Tabel 7 dapat dilihat bahwa, persentase jumlah petani yang mempunyai luas lahan 0,5-1 Ha adalah yang paling tinggi yaitu $56,67 \%$ dan diikuti oleh luas $<0,5 \mathrm{Ha}$ atau $40 \%$ dan luas lahan $>1$ Ha hanya 3,33\%.

Hubungan luas lahan dengan keikutsertaan dalam penyuluahn pertanian, dapat dilihat pada Tabel 8.

Tabel 8. Luas Lahan dan Jumlah Petani

\begin{tabular}{|l|c|c|c|}
\hline \multirow{2}{*}{$\begin{array}{c}\text { Keikutsertaan } \\
\text { Dalam Penyu- } \\
\text { luhan Perta- } \\
\text { nian }\end{array}$} & \multicolumn{3}{|c|}{ Luas Lahan (Ha) } \\
\cline { 2 - 4 } & Rendah & Sedang & Tinggi \\
\hline Rendah & 6 & 0 & 0 \\
$(28,57)$ & $(0))$ & $(0)$ \\
\hline Sedang & 10 & 1 & 2 \\
$(47,62)$ & $(20)$ & $(50)$ \\
\hline Tinggi & 5 & 4 & 2 \\
& $(23,80)$ & $(80)$ & $(50)$ \\
\hline Jumlah & 21 & 5 & 4 \\
& $(100)$ & $(100)$ & $(100)$ \\
\hline
\end{tabular}

Pada Tabel 8 terlihat bahwa petani yang mempunyai luas lahan rendah keikutsertaan pada penyuluhan pertanain persentase yang paling tinggi pada criteria sedang $(4,62 \%)$, petani yang mempunyai luas lahan sedang keikutsertaannya dalam penyuluhan pertanian sangat tinggi $(80 \%)$, dan petani yang mempunyai luas lahan yang crite- 
ria tinggi keikutsertaan dalam penyuluhan pertanian sedang (50\%) dan tinggi (50\%).

Hal ini didukung dengan uji Korelasi Spearmen, di mana diperoleh hasil $P=0.00<\alpha=0,05$. Hal ini berarti ada hubungan yang nyata atau positif antara luas lahan dan keikutsertaan dalam penyuluhan pertanian, yaitu makin tinggi (makin luas lahan pertanian), maka semakin tinggi kecenderungan keikutsertaan dalam penyuluhan pertanian.

\section{KESIMPULAN DAN SARAN}

\section{Kesimpulan}

- Karakteristik umur petani tidak mempengaruhi keikutsertaan petani dalam penyuluhan pertanian.

- Karakteristik pendidikan petani tidak mempengaruhi keikutsertaan petani dalam penyuluhan pertanian. Karakteristik pendapatan petani mempengaruhi keikutsertaan petani dalam penyuluhan pertanian.

- Karakteristik luas lahan petani mempengaruhi keikutsertaan petani dalam penyuluhan pertanian.

\section{Saran}

Disarankan kepada para penyuluh dan instansi terkait untuk dapat memperhatikan petani yang keikutsertaannya tinggi dalam penyuluhan pertanian, agar supaya penyuluhan itu dapat berhasil dan selalu memberi dampak positif bagi petani dan masyarakat pada umumnya.

\section{DAFTAR PUSTAKA}

Azwar, S. 2002. Sikap Manusia Teori dan Pengukurannya. Pustaka pelajar. Yogyakarta.

Gerungan, D. P. 1996. Psikologi Sosial. PT. Eresco Bandung. Bandung.

Hawkins, H. S. dan A. W. Van den Ban. 1999. Penyuluhan Pertanian. Kanisius. Yogyakarta

zwar, S. 2002. Sikap Manusia Teori dan Pengukurannya. Pustaka pelajar. Yogyakarta.

Gerungan, D. P. 1996. Psikologi Sosial. PT. Eresco Bandung. Bandung.

Hawkins, H. S. dan A. W. Van den Ban. 1999. Penyuluhan Pertanian. Kanisius. Yogyakarta

Mardikanto, T. 1993. Penyuluhan Pembangunan Pertanian. Sebelas Maret University Press. Surakarta.

Mardikanto, T. dan Sutarni, S. 1982. Pengantar Penyuluhan Pertanian dalam Teori dan Praktek. Hapsara. Surakarta.

Sajogyo, E dan Sajogyo, P. 1991. Sosiologi Pedesaan Jilid 1 (edt). Gadjah Mada University Press. Yogyakarta.

Siegel, S. 1997. Statistik Non Parametrik untuk Ilmu-ilmu Sosial. Gramedia. Jakarta.

Singarimbun, M dan soffan, E. I. 1981. Metode Penelitian Survey. LP3ES. Jakarta

Soekartawi. 1988. Prinsip Dasar Komunikasi Pertanian. Indonesia university Press. Jakarta.

Surakhmat, W. 1994. Pengantar Penelitian Ilmiah : Dasar Metode Teknik. Penerbit Tarsito. Bandung.

Suriatna, S. 1988. Metode Penyuluhan Pertanian. Medyatama Sarana Perkasa. Jakarta.

Winarni, S. 2001. Hubungan Karakteristik Sosial Ekonomi Petani dengan Pemilihan Ragam Metode Penyuluhan. Sebelas Maret University Press. Surakarta. 